\title{
Microbial community structure and diversity in deep-sea hydrothermal vent sediments along the Eastern Lau Spreading Centre
}

\author{
WEI Manman ${ }^{1}$, ZHANG Rubing ${ }^{3}$, WANG Yuguang ${ }^{1}$, JI Houguo ${ }^{1}$, ZHENG Jia ${ }^{1}$, \\ CHEN Xinhua $^{4}$, ZHOU Hongbo ${ }^{1,2 *}$ \\ ${ }^{1}$ School of Minerals Processing and Bioengineering, Central South University, Changsha 410083, China \\ ${ }^{2}$ Key Laboratory of Biometallurgy, Ministry of Education, Changsha 410083, China \\ ${ }^{3}$ Qingdao Institute of Bioenergy and Bioprocess Technology, Chinese Academy of Sciences, \\ Qingdao 266101, China \\ ${ }^{4}$ Third Institute of Oceanography State, Oceanic Administration, Xiamen 361005, China \\ Received 19 May 2011; accepted 24 April 2012
}

CThe Chinese Society of Oceanography and Springer-Verlag Berlin Heidelberg 2013

\begin{abstract}
The aim of this study is to investigate microbial structures and diversities in five active hydrothermal fields' sediments along the Eastern Lau Spreading Centre (ELSC) in the Lau Basin (southwest Pacific). Microbial communities were surveyed by denatured gradient gel electrophoresis (DGGE) and clone library analysis of 16S rRNA genes. The differences in microbial community structures among sediment samples from the five deep-sea hydrothermal sites were revealed by DGGE profiles. Cluster analysis of DGGE profiles separated the five hydrothermal samples into two groups. Four different $16 \mathrm{~S}$ rRNA gene clone libraries, representing two selected hydrothermal samples (19-4TVG8 and 19-4TVG11), were constructed. Twenty-three and 32 phylotypes were identified from 166 and 160 bacterial clones respectively, including Proteobacteria, Bacteroidetes, Firmicutes, Nitrospirae and Planctomycetes. The phylum Proteobacteria is dominant in both bacterial libraries with a predominance of Gamma-Proteobacteria. A total of 31 and 25 phylotypes were obtained from 160 and 130 archaeal clones respectively, including Miscellaneous Crenarchaeotic Group, Marine Group I and III, Marine Benthic Group E, Terrestrial Hot Spring Crenarchaeota and Deep-sea Hydrothermal Vent Euryarchaeota. These results show a variety of clones related to those involved in sulfur cycling, suggesting that the cycling and utilization of sulfur compounds may extensively occur in the Lau Basin deep-sea hydrothermal ecosystem.
\end{abstract}

Key words: microbial diversity, deep-sea hydrothermal vent, DGGE, 16S rRNA gene clone libraries

Citation: Wei Manman, Zhang Rubing, Wang Yuguang, Ji Houguo, Zheng Jia, Chen Xinhua, Zhou Hongbo. 2013. Microbial community structure and diversity in deep-sea hydrothermal vent sediments along the Eastern Lau Spreading Centre. Acta Oceanologica Sinica, 32(2): 42-51, doi: 10.1007/s13131-013-0276-6

\section{Introduction}

Microbial populations thriving in deep-sea hydrothermal vents have been extensively investigated since the discovery of these environments and their vast associated biota (Van Dover, 2000). The environment is characterized by steep environmental gradients of temperature, $\mathrm{pH}$, redox potential and metal compounds (McCollom and Shock, 1997). It is generally regarded that such an environment provides diversity niches for microbial communities and has been also a major source of novel microbes with unique physicochemical characteristics. In the previous studies, direct isolation of microorganisms as well as the use of molecular techniques has revealed the presences of several different physiological and phylogenetic groups of prokaryotes in the extreme marine environment (Jeanthon, 2000). Although numerous novel lineages of uncultivated bacteria and archaea habitated in deep-sea hydrothermal fields have been successfully detected (Takai et al., 2003; Schrenk et al., 2003), a large number of unknown microbial resources still need to be identified and explored in other deep-sea hydrothermal fields.

The ELSC including the Valu Fa Ridge (VFR) is an about $400 \mathrm{~km}$ long spreading centre associated with the opening of the Lau Basin, a young back-arc basin with active spreading ridges and off-axis seamount volcanoes, behind the Tonga zone. This field displays unique geochemical and biologic characteristics with high concentrations of metal sulfides and elemental sulfur relative to hydrothermal vent systems of the East Pacific Rise (EPR) and other well-studied vent sites in the Pacific Ocean (Fouquet et al., 1991; Michael and Seewald, 2007; Herzig and Hannington, 1995). A variety of potential electron donors (sulfides, organic $\mathrm{C}, \mathrm{CH}_{4}$, and $\mathrm{Fe}$ ) and electron acceptors $\left(\mathrm{O}_{2}, \mathrm{SO}_{4}^{2-}\right.$, and $\left.\mathrm{CO}_{2}\right)$ have been identified in these environments, potentially supporting the growth of diverse heterotrophic and autotrophic prokaryotes. Additionally,

Foundation item: The China Ocean Mineral Resources Research and Development Association under contract No. DYXM-115-02-2-07; the State Oceanic Administration of People's Republic of China under contract No. 200805032; the National Natural Science Foundation of China under contract Nos 50621063 and 40646029.

Corresponding author, E-mail: zhouhb@mail.csu.edu.cn 
the formation of this back-arc basin is a relatively recent geological event and the basin has been hydrothermally active for only a short time. The ELSC was chosen as a representative because it provides diverse microbial niches due to steep physical and chemical gradients. These attributes make the Lau Basin the best active hydrothermal vent sites to study prokaryotic phylogenetic and metabolic diversity (Michael and Seewald, 2007). The information about the distribution, diversity, and composition of the microbial communities at Lau Basin deep-sea hydrothermal vents was relatively little, with only several short comments published (Michael and Seewald, 2007). Thus a thorough investigation on prokaryotic communities in this hydrothermal vent system is quite necessary.

The objectives of this study were to investigate the prokaryotic diversity in sediments from five deep-sea hydrothermal vents along the ELSC in the Lau Back Arc Basin and to analyze the interrelationship between environment and microbial diversity, which will generate data that could facilitate the isolation of novel microbes with unique functional characteristics.

\section{Materials and methods}

\subsection{Site description and sample collection}

Five sediment samples were collected from deep-sea hydrothermal vent fields along the ELSC during round-the-world ocean research of Dayangyihao in May 2007. As shown in Table 1, sample 19-4TVG8 was from the VFR at southern ELSC and the other four samples were collected from the main ELSC. Immediately after sampling, they were labeled and stored in sterile plastic tubes at $-80^{\circ} \mathrm{C}$ until they were processed.

Sediment samples were analyzed for total nitrogen (TN), organic carbon and sulfate concentrations. Sediment temperature and $\mathrm{pH}$ were measured in situ. Pore water sulfate was measured by ion chromatography. Sediment organic carbon and total nitrogen content were measured in the laboratory with a PE 2400 Series II CHNS/O analyzer (Perkin Elmer, USA).

\subsection{Microscopic counts}

The total cell numbers in each sample were determined by direct microscopic counts, using DAPI $\left(4^{\prime}, 6^{\prime}\right.$-diamidino2-phenylindole) fluorochrome staining technique. Sediment samples were placed on ice and sonicated to dislodge cells from sediment particles, and then were fixed with buffered polyformaldehyde at a final concentration of $1 \%$. An aliquot of the fixed sediment slurry $(10 \mu \mathrm{l})$ was diluted 1000 -fold in sterile PBS buffer $(0.9 \mathrm{~g} \mathrm{NaCl}, 15 \mathrm{mmol} / \mathrm{L}$ sodium phosphate buffer, pH 7.4), thoroughly shaken, and filtered through a black polycarbonate membrane. Staining with DAPI was performed for 20 min in the dark and cells were counted with an epifluorescence microscopy (Olympus BX-60 M). Each sample was measured in triplicate.

\subsection{Genomic DNA extraction}

Total community genomic DNA was extracted from $5 \mathrm{~g}$ of each sediment sample by the method of Zhou et al. (1996) with some modifications. The protocol encompassed grinding, three cycles of freezing and thawing, chemical lyses in a highsalt extraction buffer $(1.5 \mathrm{~mol} / \mathrm{L} \mathrm{NaCl})$ by heating of the suspension in the presence of sodium dodecyl sulfate (SDS) and cetyltrimethyl ammonium bromide (CTAB), and a proteinase $\mathrm{K}$ step. The obtained DNA was stored at $-20^{\circ} \mathrm{C}$ and used as the template for further PCR amplification.

\subsection{PCR amplification of $16 S \mathrm{rRNA}$ gene fragments}

In order to assess the prokaryotic diversity of the sediment samples, DGGE and restriction fragment length polymorphism (RFLP) analysis of 16S rRNA gene were performed. For construction of clone libraries, Bacteria-specific primers 27F (5'-AGAGTTTGATCCTGGCTCAG-3') and 1492R (5'-GGTTACCTTGTTACGACTT- $3^{\prime}$ ) and Archaea-specific 21F (5'-TTCCGGTTGATCCYGCCGGA-3') and 958R (5'-YCCGGCGTTGAMTCCAATT- $\left.3^{\prime}\right)$ were used. Each PCR mixture $(50 \mu \mathrm{l})$ contained 2.5 $\mathrm{mmol} / \mathrm{L} \mathrm{MgCl}_{2}, 0.2 \mathrm{mmol} / \mathrm{L}$ dNTP, $0.2 \mathrm{pmol} / \mathrm{L}$ each primer, $1 \times$ PCR buffer (Fermentas), and $1 \mathrm{U}$ of Taq DNA polymerase (Fermentas). An initial denaturation step of $5 \mathrm{~min}$ at $94^{\circ} \mathrm{C}$ was followed by 32 cycles of $94^{\circ} \mathrm{C}$ for $45 \mathrm{~s}, 55^{\circ} \mathrm{C}$ for $40 \mathrm{~s}$, and $72^{\circ} \mathrm{C}$ for $2 \mathrm{~min}$. The final extension step was $72^{\circ} \mathrm{C}$ for $10 \mathrm{~min}$. PCR amplifications were purified with the Gel Extraction Kit (Bioteke Corporation, Beijing, China) in accordance with the manufacturer's instructions.

For DGGE analysis, about 200-bp fragments of 16S rRNA genes were amplified by primers 341F-GC (5'-CGCCCGCCGCGCGCGGCGGGCGGGGCGGGGGCACGGGGGGCCTACGGGAGGCAGCAG- $\left.3^{\prime}\right)$ and 518R(5'-GTATTACCGCGGCTGCTGG-3') (Muyzer et al., 1996) for bacteria and primers PARCH 340F-GC (5' CGCCCGCCGCGCCCCGCGCCCGTCCCGCCGCCCCCGCCCCCCTACGGGGYGCASCAG-3') and PARCH 519R (5'-TTACCGCGGCKGCTG-3') (Ovreas et al., 1997) for archaea, respectively. To increase the specificity of the amplification and reduce the formation of spurious by-products, a touchdown PCR was performed as follows: the annealing temperature was set to $65^{\circ} \mathrm{C}$ and decreased by $0.5^{\circ} \mathrm{C}$ at every cycle for 20 cycles, and then 15 additional cycles were performed. Denaturation was carried out at $94^{\circ} \mathrm{C}$ for $1 \mathrm{~min}$, the annealing time was $1 \mathrm{~min}$, and the primer extension was $72^{\circ} \mathrm{C}$ for $1 \mathrm{~min}$. A final extension at $72^{\circ} \mathrm{C}$ for $10 \mathrm{~min}$ was performed.

\subsection{DGGE analysis}

DGGE was carried out in a CBS Scientific DGGE-2401 system (C.B.S. Scientific Company, Inc., Del Mar, CA, USA) by a previously described method with slight modifications (Muyzer et al., 1996). PCR products were resolved on polyacrylamide gels $(8 \%, \mathrm{w} / \mathrm{v})$ in $1 \times \mathrm{TAE}(20 \mathrm{mmol} / \mathrm{L}$ Tris-Cl, $10 \mathrm{mmol} / \mathrm{L}$ acetate, $0.5 \mathrm{mmol} / \mathrm{L} \mathrm{Na}_{2}$ EDTA) using denaturing gradient from $40 \%$ to $55 \%$ (for bacteria) or $40 \%$ to $60 \%$ (for archaea) where $100 \%$ denaturant contained $7 \mathrm{~mol} / \mathrm{L}$ urea and $40 \%$ formamide. Electrophoresis was carried out at a constant voltage of $200 \mathrm{~V}$ and a temperature of $60^{\circ} \mathrm{C}$ for $3-5 \mathrm{~h}$. After electrophoresis, the gels were stained for $20 \mathrm{~min}$ with ethidium bromide and visualized on a UV gel documentation system and photographed.

\subsection{Clone libraries and RFLP analysis}

Four 16S rRNA gene clone libraries were constructed, one bacterial and one archaeal for hydrothermal sediment 19-4TVG8 and 19-4TVG11 respectively. For each library, the cleaned PCR products were linked with pGEM T-Vector (Promega, Madison, WI), transformed into E. coli DH5 $\alpha$ competent cells, and then positive clones were screened out through blue and white spot selection. About 160 white colonies for each library were randomly selected and stored on agar plates. Inserts were subsequently amplified from positive colonies with primers specific for the vector, M13F (5'GTAAAACGACGGCCAGT- $3^{\prime}$ ) and M13R (5'-CAGGAAACAGCTA TGAC-3'). The colony PCR products were digested separately with $2.5 \mathrm{U}$ of MspI (Fermentas) and Hin6I (Fermentas) in a 20 $\mu \mathrm{l}$ reaction mixture as recommended by the manufacturer and 
visualized on $3 \%(\mathrm{w} / \mathrm{v})$ agarose gels stained with ethidium bromide. The resulting restriction digest patterns were compared and analyzed between samples.

\subsection{Phylogenetic and cluster analysis}

The DGGE fingerprints were analyzed using the Gel Pro Analyzer 3.1 (Media Cybernetics, MD, USA) for band detection, and then comparisons of microbial community composition$\mathrm{s}$ of five sediment samples were performed by cluster analysis using NTSYS-pc software package (Rohlf, 2002). Dendrogram$\mathrm{s}$ were constructed by the unweighted pair group method with arithmetic mean (UPGMA) groupings with a similarity coefficient matrix. By comparing the size and number of digested fragments, clones with unique RFLP patterns were selected for sequencing. The sequences were firstly assembled, with vector trimming, and then compared with those in GenBank database by BLAST search to find closely related sequences. Sequences with being greater than and equaling to $97 \%$ similarity were assigned to the same phylotype. The sequences were aligned with their most similar species using Clustal X (version 1.8). The phylogenetic trees were constructed from evolutionary distances using the neighbor-joining method with bootstrap analysis for 1000 replicates.

\subsection{Diversity indices and statistical analysis}

Rarefaction analysis was performed and diversity indices were calculated to analyze the microbial diversity within each clone library. The rarefaction curves were constructed using Analytic Rarefaction 1.3 (http://www.uga.edu/strata/software/index.html). The coverage of the libraries was calculated as defined by Good (1953), with the following formula:

$$
C=\left(1-n_{1} / N_{s}\right) \times 100,
$$

where $n_{1}$ is the number of phylotypes appearing only once in a library and $N_{s}$ is the library size. The Shannon's index $\left(H^{\prime}\right)$ of diversity and the Simpson's index $(D)$ were calculated by the equation

$$
H^{\prime}=-\sum_{i=1}^{s} p_{i} \ln p_{i} \text { and } D=1-\sum_{i=1}^{s} p_{i}^{2},
$$

where $p_{i}$ is the proportion of clones belonging to the $i$ th phylotype and $s$ is the total number of phylotypes. Evenness was calculated with the formula $E=\mathrm{e}^{H^{\prime}} / N$, where $H^{\prime}$ is the Shannon index of diversity and $N$ is the total number of phylotypes (Lauritzen and Bottrell, 1994). The phylotype compositions of the clone libraries were compared using the Sorensen index

$$
S=2 \times c /(a+b),
$$

where $c$ is the number of phylotypes found in both Sample A and Sample B; $a$ is the number of phylotypes in Sample A; and $b$ is the number of phylotypes in Sample B (Magurran, 1988).

\subsection{Nucleotide sequence accession numbers}

The 16S rRNA gene sequences obtained in this study have been deposited in the GenBank database under accession numbers GQ848371 to GQ848480.

\section{Results}

\subsection{Physicochemical characteristics of sediments and total cell counts}

Physicochemical characteristics of the hydrothermal sediments (Table 1) varied considerably amongst the five samples. All sediments displayed nearly neutral $\mathrm{pH}$, ranging from 6.22 to 7.72. The content of organic carbon and total nitrogen in the sediments was in the range of $0.29 \%-1.61 \%$ and $0.02 \%-0.07 \%$ respectively, with the highest values in the sediment 19-4TVG8 and the lowest values in the sediment 19-4TVG11 (Table 1). The physicochemical characteristics of Samples 19-4TVG8 and 194TVG11 represented the greatest difference in the five samples.

Total cell numbers were in the range of $6.89 \times 10^{7}$ to $4.26 \times 10^{8}$ cells/g of wet sediment and showed certain variation$\mathrm{s}$ among five sediment samples. No significant correlation between total cell numbers and physicochemical characteristics of sediment samples were found. Comparing the physicochemical characteristics of the samples, it was found that Samples 194TVG8 and 19-4TVG11 were the most distinct from each other.

\subsection{DGGE analysis}

DGGE analyses of bacterial and archaeal 16S rRNA genes were performed to compare the microbial compositions of the five sediment samples, and DGGE banding patterns were used to construct dendrograms (Fig. 1). DGGE banding patterns revealed that there were some differentiations in both bacterial and archaeal community structures among hydrothermal sediment samples from different sites. These differences can also be visualized in the inferred genetic relationships of the microbial populations given in the dendrogram for cluster analysis. The bacterial DGGE profiles of the five sediment samples were separated into two clusters, with the lowest similarity coefficient 0.59; the archaeal DGGE profiles were separated into three clusters, with the lowest similarity coefficient 0.47 . The bacterial and archaeal patterns of 19-4TVG8 and 19-4TVG11 were clustered to different groups, suggesting that the microbial community structures of both samples greatly differed from each other among the five samples. As mentioned above, the physico-

\begin{tabular}{|c|c|c|c|c|c|}
\hline \multirow[t]{2}{*}{ Parameter } & \multicolumn{5}{|c|}{ Sample } \\
\hline & 19-4TVG2 & 19-4TVG8 & 19-4TVG11 & 19-4TVMC4 & 19-4TVMC8 \\
\hline South latitude $/\left(^{\circ}\right)$ & 19.7418 & 22.2158 & 20.9280 & 19.6927 & 20.6665 \\
\hline West longitude $/\left(^{\circ}\right)$ & 175.9561 & 176.6072 & 176.2401 & 175.9511 & 176.1253 \\
\hline Depth/m & 2350 & 1722 & 2255 & 2699 & 2457 \\
\hline Temperature $/{ }^{\circ} \mathrm{C}$ & ND & 84 & 114 & ND & ND \\
\hline $\mathrm{pH}$ & 7.66 & 7.72 & 6.22 & 6.25 & 7.49 \\
\hline Organic carbon (\%) & 0.51 & 1.61 & 0.29 & 0.77 & 0.76 \\
\hline Total nitrogen $(\%)$ & 0.04 & 0.07 & 0.02 & 0.05 & 0.02 \\
\hline Sulfate concentration $/ \mathrm{mmol} \cdot \mathrm{L}^{-1}$ & 16.9 & 19.8 & 13.5 & 17.4 & 23.2 \\
\hline Total cell counts $/ \times 10^{7}$ cells. $g^{-1}$ & $7.48 \pm 0.26$ & $42.6 \pm 1.16$ & $6.89 \pm 0.15$ & $14.7 \pm 0.89$ & $32.1 \pm 1.52$ \\
\hline
\end{tabular}
chemical characteristics and cell counts of Samples 19-4TVG8

Table 1. Characteristics of the hydrothermal samples and microbial communities analysis

Notes: ND represents not determined. 

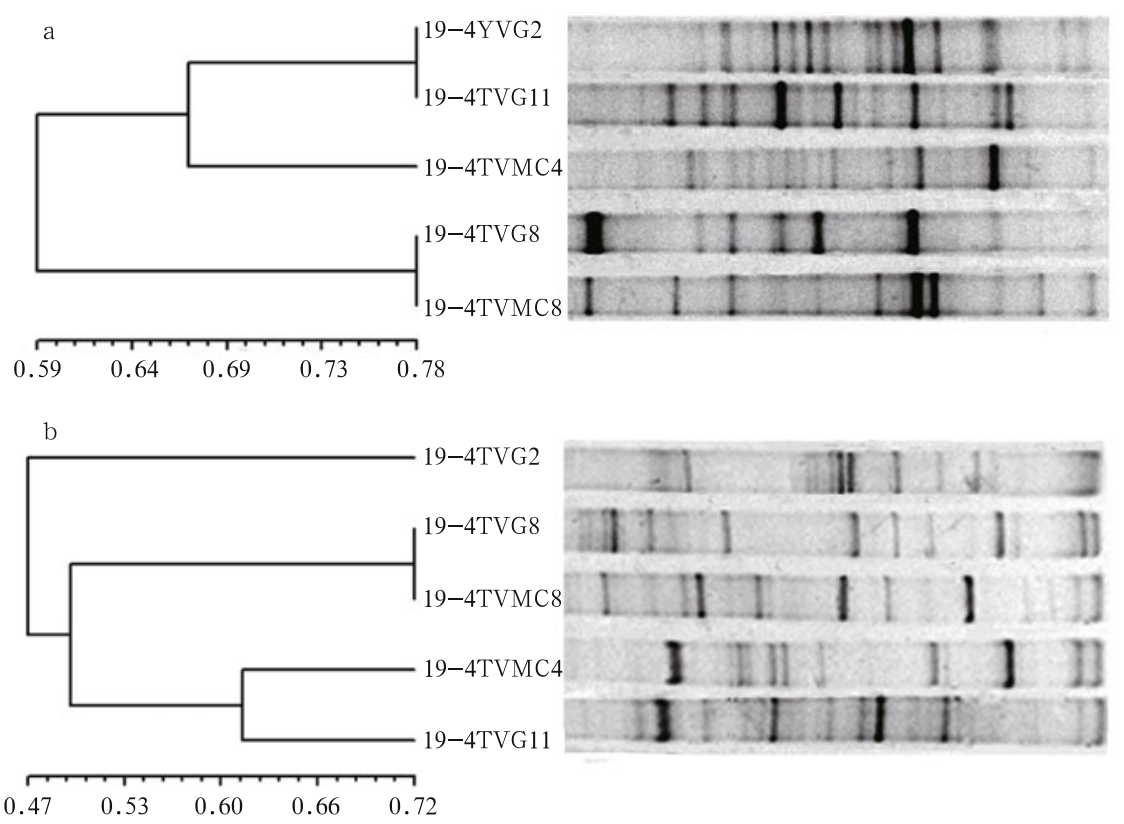

Fig.1. Cluster analysis of the profiles obtained from DGGE banding patterns for bacterial (a) and archaeal (b) communities. The dendrogram was generated with NTSYS version 2.10 using UPGMA.

and 19-4TVG11 were the greatest different in the five samples. The difference in microbial community structure of Samples 19-4TVG8 and 19-4TVG11 may correlate with variations in physicochemical characteristics of the two samples.

\subsection{Clone libraries and phylogenetic analysis}

DGGE can resolve the diversity of only the most dominant populations $(>1 \%)$ and separate only relatively small fragments, up to $500 \mathrm{bp}$. Since the DGGE analysis revealed a certain degree of similarity among banding patterns for the five hydrothermal samples and distinct division of two clusters, we selected two samples (19-4TVG8 and 19-4TVG11) as a representative for a more thorough characterization. Bacterial and archaeal 16S rRNA gene clone libraries were constructed for sample 19-4TVG8 and 19-4TVG11, respectively. A total of 616 clones from the four clone libraries were screened by RFLP and grouped into identical restriction patterns (phylotypes). The phylogenetic trees of the bacteria and archaea from Samples 19-4TVG8 and 19-4TVG11 were constructed on the basis of 16S rRNA sequences as shown in Figs 2 and 3.

In two bacterial clone libraries, 19-4TVG8BA and 194TVG11BA were composed of 166 and 160 clones that grouped into 23 and 32 phylotypes, respectively (Fig. 2). In the library 194TVG8BA, the phylotypes could be divided into eight lineages, as follows: Gamma-Proteobacteria (41.57\% of the total clones), Epsilon-Proteobacteria (24.1\%), Delta-Proteobacteria (18.67\%), Alpha-Proteobacteria (2.41\%), Bacteroidetes (6.02\%), Firmicutes (3.01\%), Nitrospirae (2.41\%), Planctomycetes (1.81\%). In the library 19-4TVG11BA, the phylotypes could be divided into seven lineages: Gamma-Proteobacteria (37.5\% of the total clones), Epsilon-Proteobacteria (8.13\%), Delta-Proteobacteria (21.86\%), Alpha-Proteobacteria (20\%), Bacteroidetes (5.63\%), Nitrospirae (5\%), Planctomycetes (1.88\%). Gamma-Proteobacteria and Epsilon-Proteobacteria were the most prominent groups of microorganisms represented in both bacterial clone libraries. The Proteobacteria were highly dominant, accounting for nearly $90 \%$ of the total clones in both bacterial libraries and being divided into four subclasses Alpha-, Delta-, Epsilon-, and Gamma-Proteobacteria. Within the Proteobacteria, the Gamma-Proteobacteria was the most abundant phylogenetic group, accounting for $41.57 \%$ of the total clones in the library $19-4$ TVG8BA and $37.5 \%$ of the clones in the library 19-4TVG11BA, respectively. The distributions of the Alphaand Epsilon-Proteobacteria were different in the two bacterial clone libraries, with a higher richness and greater diversity for Alpha-Proteobacteria in the 19-4TVG11BA library and EpsilonProteobacteria in the19-4TVG8BA library. The proportions of Delta-Proteobacteria in both bacterial libraries were similar, comprising $18.67 \%$ of the total clones in library $19-4$ TVG8BA, and comprising $21.86 \%$ in library $19-4$ TVG11BA. The Firmicutes appeared only in library 19-4TVG8BA and did not in the library 19-4TVG11BA. The families of Bacteroidetes, Nitrospirae, Planctomycete were present in both bacterial libraries with similar low frequencies between $1.8 \%$ and $6.1 \%$. Some phylotypes classified in the Proteobacteria were closely related to cultured species (Fig. 2). However, other bacterial phylotypes had low similarity $(<95 \%)$ to the sequences of cultured species in public databases. This result suggests that some novel bacterial species are present at the deep-sea hydrothermal vent fields along the ELSC.

In the two archaeal clone libraries, 31 and 25 archaeal phylotypes were defined from 160 and 130 clones in the 194TVG8AR and 19-4TVG11AR libraries, respectively (Fig. 3). The 19-4TVG8AR clone library contained 58\% of Crenarchaeota and $42 \%$ of Euryarchaeote, whereas there was a higher richness and greater diversity for Crenarchaeota (85\%) in the 19-4TVG11AR library. These phylotypes had a low similarity (less than $90 \%$ ) to those isolated species in the database and were difficult to confidently determine their taxonomic status. Thus, the physiolog- 


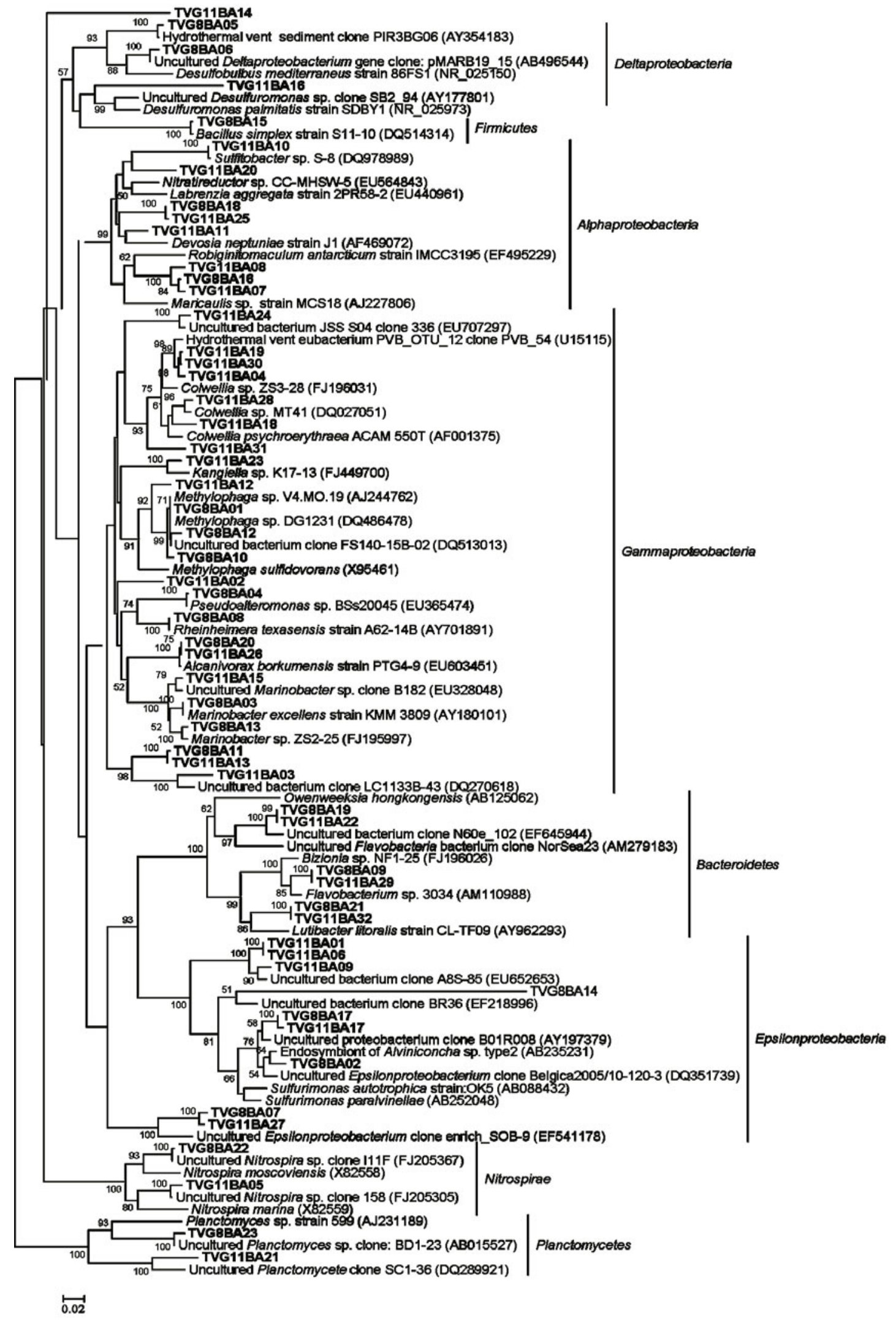

Fig.2. Phylogenetic trees of the bacterial 16S rRNA gene sequences obtained from the clone library 19-4TVG8BA and 19-4TVG11BA. Clones detected in this study are indicated in bold. The tree was conducted using sequences of comparable region of the 16S rRNA gene sequences available in public databases. Neighbor-joining analysis using 1000 bootstrap replicates was used to infer tree topology. 


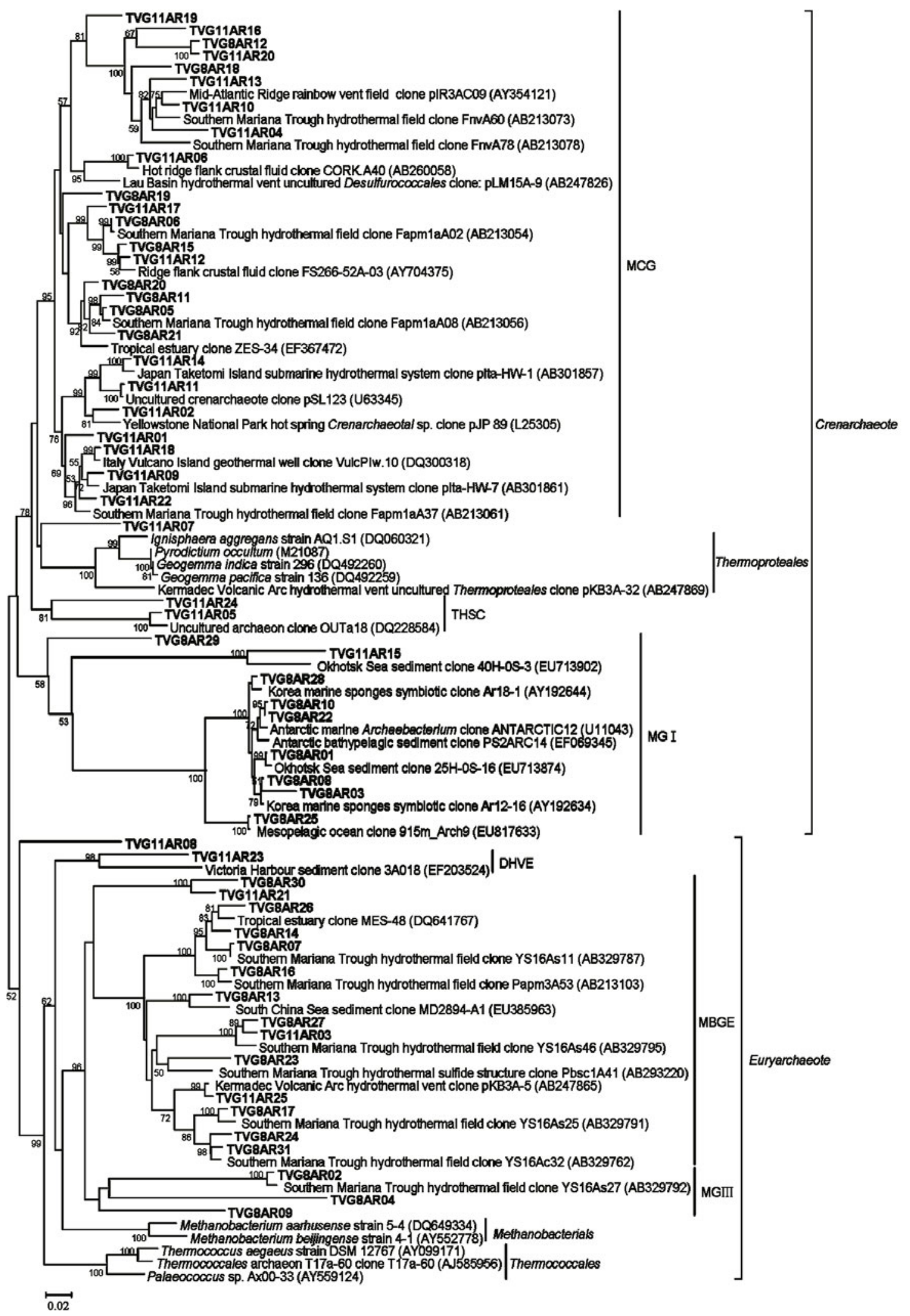

Fig.3. Phylogenetic trees of the archaeal 16S rRNA gene sequences obtained from the clone library 19-4TVG8AR and 19-4TVG11AR. Clones detected in this study are indicated in bold. The tree was conducted using sequences of comparable region of the 16S rRNA gene sequences available in public databases. Neighbor-joining analysis using 1000 bootstrap replicates was used to infer tree topology. 
ical characteristics of these uncultured phylotypes are unclear. According to the previous studies, the archaeal phylotypes recovered were associated with the following groups: the Miscellaneous Crenarchaeotic Group (MCG) (Inagaki et al., 2003a), Marine Group I and III (MGI and MGIII) (Fuhrman et al., 1992; Fuhrman and Davis, 1997), Marine Benthic Group E (MBGE) (Vetriani et al., 1999), Terrestrial Hot Spring Crenarchaeota (THSC) and Deep-sea Hydrothermal Vent Euryarchaeota (DHVE) (Takai and Horikoshi, 1999) (Fig. 3). In addition, the phylotypes TVG11AR07 and TVG11AR08 were not clearly classified in these groups. The TVG11AR07 clone had 99\% similarity to uncultured clone FnvA87 from crustal fluids in back-arc hydrothermal fields of the Southern Mariana Trough. The TVG11AR08 clone exhibited 92\% similarity to the clone LP30MA94 obtained from phreatic limestone sinkholes in northeastern Mexico. Until now, no cultured member of all these archaeal groups, with the exception of MGI, has been discovered.

\subsection{Comparison and statistical analysis of clone libraries}

The number of clones, phylotypes, and biodiversity indices calculated for the four clone libraries were summarized in Table 2. The coverage of the clone libraries was high, ranging from $80 \%$ to $86 \%$. The high coverage values combined with the saturated rarefaction curves (data not shown) suggest that most phylotypes present in the microbial communities were identified in this study. The results of the Shannon index, Simpson index and Coverage, indicate that the 19-4TVG8 archaeal population was the most diverse, while the 19-4TVG8 bacterial population was the least diverse. In addition, the 19-4TVG11 bacterial diversity was higher in both species richness and evenness than that of 19-4TVG8, while species richness and evenness were similar between two archaeal populations.

The microbial compositions of the clone libraries were compared by calculating the Sorensen similarity index. Phylotype comparisons between the 19-4TVG8 and 19-4TVG11 archaeal libraries reveal that four phylotypes gave the same bestBLAST matches, for a lower similarity value of 0.14 . The similarity value of the two bacterial libraries $(0.36)$ was substantially higher than that determined for the archaeal libraries (0.14). About $43 \%$ of the total 19-4TVG8 phylotypes had the same bestBLAST matches as the 19-4TVG11 phylotypes. The uniqueness of the microbial communities in this study was estimated by comparing the degree of relatedness of the microbial sequences we obtained with their closest matches in GenBank. Overall, $36 \%$ of the bacterial phylotypes and $39 \%$ of the archaeal phylotypes were related to the existing sequences at being less than $95 \%$ identity, which suggests that these sequences represent novel microbial genera not yet recovered from any other environment.

Table 2. Number of clones and phylotypes analyzed for the four 16S rRNA gene clone libraries and their diversity indices

\begin{tabular}{lccccccc}
\hline Clone library & $\begin{array}{c}\text { Total No. } \\
\text { of clones }\end{array}$ & $\begin{array}{c}\text { No. of } \\
\text { phylotypes }\end{array}$ & $\begin{array}{c}\text { Coverage } \\
(\%)\end{array}$ & $\begin{array}{c}\text { Shannon } \\
\text { index }\left(H^{\prime}\right)\end{array}$ & $\begin{array}{c}\text { Simpson's } \\
\text { index }(D)\end{array}$ & $\begin{array}{c}\text { Evenness } \\
(E)\end{array}$ & $\begin{array}{c}\text { Sorensen } \\
\text { similarity index }\end{array}$ \\
\hline 19-4TVG8BA & 166 & 23 & 86 & 2.12 & 0.89 & 0.82 & 0.36 \\
19-4TVG11BA & 160 & 32 & 80 & 2.39 & 0.95 & 0.93 & 0.14 \\
19-4TVG8AR & 160 & 31 & 81 & 2.42 & 0.96 & 0.95 & 0.95 \\
19-4TVG11AR & 130 & 25 & 82 & 2.33 & 0.95 & 0.95 & \\
\hline
\end{tabular}

\section{Discussion}

The present study provides the first characterization of the microbial diversity present in the deep-sea hydrothermal ven$t$ fields found at the ELSC of Lau Basin and the results show the existence of a variety of bacterial and archaeal phylotype$\mathrm{s}$ in hydrothermal samples along the ELSC, as represented in the DGGE gels and 16S rRNA gene clone libraries. Our results suggest that deep-sea hydrothermal vents along the ELSC are likely to provide habitats for phylogenetically and metabolically diverse microorganisms.

\subsection{Diversity of bacteria and archaea}

All bacterial groups identified in this study are widespread in deep-sea hydrothermal vent environments and may participate in a variety of biogeochemical processes. Generally, Gamma-Proteobacteria are very diverse in marine plankton, and also are universal and abundant in deep-sea hydrothermal fields (López-García et al., 2001). Gamma-Proteobacteria not only accounted for the largest proportion in our bacterial clone libraries, but also they were very diverse. Similar results were also found at the Juan de Fuca Ridge hydrothermal vent based on geochip analysis, which demonstrate the prevalence and predominance of bacteria belonging to the gamma subdivision of Proteobacteria (Wang et al., 2009).

Most members of Delta-Proteobacteria are strictly anaerobic sulfate reducing bacteria, reducing sulfate or sulfite using $\mathrm{H}_{2}$ or an organic molecule as electron donors, and may par- ticipate in the reduction processes of sulfate, sulfur or $\mathrm{Fe}^{3+}$ (Abildgaard et al., 2006; Vandieken et al., 2006). In this study, sequences related to Delta-Proteobacteria belonged to the genera Desulfobulbus and Desulfuromonas, and clustered with those hydrothermal sediment clones obtained from the Mid-Atlantic Ridge (MAR) and the EPR (Nercessian et al., 2005). This suggest$\mathrm{s}$ that potentially active sulfate-reducing metabolism is present in deep-sea hydrothermal fields along the ELSC.

Interestingly, the distributions of Epsilon-Proteobacteria, Alpha-Proteobacteria and Firmicutes in the clone libraries 19-4TVG8BA and 19-4TVG11BA were significantly different (Fig. 2). Several detected phylotypes belonging to EpsilonProteobacteria were related to either Sulfurimonas sp. or environmental sequences. The previous studies indicate that Epsilon-Proteobacteria inhabited in deep-sea hydrothermal fields are comprised of mesophilic to moderately thermophilic chemolithoautotrophs capable of oxidizing hydrogen and sulfur compounds with nitrate, oxygen, and sulfur compounds as terminal electron acceptors (Nercessian et al., 2005; Campbell et al., 2006; Moussard et al., 2006). In the present study, the proportion of Epsilon-Proteobacteria in the library 19-4TVG8BA was significantly higher than that in the library 19-4TVG11BA. The Alpha-Proteobacteria, represented in our study by Rhodobacterales and Rhizobialesthes, were found in both bacterial libraries, with a higher proportion in the library 19-4TVG11BA. Members of the Alpha-Proteobacteria, especially Roseobacter clade, are metabolically versatile and widespread 
in marine habitats. Strikingly, several phylotypes detected in this study were related to the genera Nitrobacter and Sulfitobacter, which are autotrophic nitrite-oxidizing bacteria and heterotrophic sulfite-reducing bacteria, respectively. Firmicutes were detected only in the libraries 19-4TVG8BA, and absent in the libraries 19-4TVG11BA. Representatives of Firmicutes from the libraries 19-4TVG8BA are Bacillus sp., moderately thermophilic bacteria oxidizing a wide range of organic substrates (Miroshnichenko and Bonch-Osmolovskaya, 2006). The differences in physicochemical conditions of the two sites, such as temperature, oxygen, nutrient conditions and substrate availability, may explain the observed variability in bacterial community compositions, e.g., the lack of Firmicutes in the library 19-4TVG11BA may be attributed to the high sampling temperature $\left(114^{\circ} \mathrm{C}\right)$ and the low organic carbon content of the corresponding sample. It is generally believed that bacterial community structures in deep-sea hydrothermal vent fields are mainly defined by complex interactions of biogeochemical parameters.

Bacteroidetes, Nitrospirae and Planctomycete were also found in both two bacterial clone libraries although with a small portion $(<10 \%)$. The Nitrospirae bacteria may also be nitrifiers, important in the nitrite oxidization process and carbon fixation in the deep-sea environments (Ehrich et al., 1995). Bacteroidetes and Planctomycete are ubiquitous in marine environments, which mainly reside in microaerobic environments and are related to degradation of carbohydrate polymer (Ravenschlag et al., 2001).

Our study show the presence of MCG, MBGE, MGI, MGIII, THSC and DHVE in deep-sea hydrothermal vent fields along the ELSC, which is the first report of the detection of various unique archaeal phylotypes in these fields. MBGE and MCG clones were the most abundant groups in both archaeal clone libraries. MBGE consists of a cluster of closely related sequences within the Euryarchaeota and the detected phylotypes affiliated in this group were related to environmental sequences detected in deep-sea environments (Huber et al., 2005; Heijs et al., 2008; Takai et al., 2008). In this study, no MBGE clones appeared to be specifically related to known archaeal isolates, but their phylogenetic position between members of the Methanobacteriales and the Methanosarcinales suggests a possible methanogenic phenotype. MCG was previously designated the terrestrial miscellaneous crenarchaeotic group, but was given the recent reports of marine, hot and cold, surface and subsurface environments (Vetriani et al., 1999; Inagaki et al., 2003a; Heijs et al., 2008; Parkes et al., 2005; Rogers and Amend, 2005; Teske, 2006). Most of the phylotypes in the MBGE and MCG in the present study were related to the sequences retrieved from hydrothermal fields of the MAR, Southern Mariana Trough, or Taketomi Isoland (Fig. 3).

Phylotypes in the MGI and MGIII were also retrieved from the 19-4TVG8 and 19-4TVG11 samples. The MGI and MGIII archaea are abundant and ubiquitous in ocean environments (Fuhrman et al., 1992; Fuhrman and Davis, 1997). The clone TVG11AR23 was classified within the DHVE group which is considered to have a significant impact in hydrothermal habitats. It has been observed that members of DHVE group represented a widespread euryarchaeotal lineage in deep-sea hydrothermal fields of the EPR and Central Indian Ocean Ridge (Hoek et al., 2003; Kormas et al., 2006). But cultured member of this group has been poorly reported. Reysenbach et al. (2006) reported the isolation and cultivation of an archaeon belonging to the D-
HVE2 group, which is an obligate thermoacidophilic sulphur or iron reducing heterotrophic archaeon.

The physiological characteristics of all these groups, with the exception of MGI, are unknown because no cultivated species exist. In this study, most archaeal sequences may be regarded as novel (not previously cultured) phylotypes and have a high probability of representing new taxa. Nevertheless, our results suggest the presence of unique and diverse archaeal communities at the deep-sea hydrothermal vent fields along the ELSC.

The recent studies based on analysis of $16 \mathrm{~S}$ rRNA gene sequences have demonstrated that archaea are much more diverse and widespread than previously suspected (Massana et al., 2000; Kormas et al., 2006). Also, several reports have indicated a distinct distribution of the marine environment between Crenarchaeota and Euryarchaeota, with Euryarchaeota dominant in the surface zone and Crenarchaeota dominant in deepsea area (Massana et al., 2000; Pernthaler et al., 2002). In the present study, it was found that Crenarchaeota were dominant in deep-sea hydrothermal sediments along the ELSC, which is consistent with other studies on deep-sea hydrothermal environments (Page et al., 2008; Brazelton et al., 2006).

\subsection{Sulfur-related metabolism in hydrothermal vents}

The ability to metabolize sulfur compounds appears to be widespread among microorganisms of widely different phylogenetic and physiological types in deep-sea hydrothermal environments (Sievert et al., 2007). The detection of sequences involved in sulfur cycles, such as those belonging to Sulfuricurvum, Sulfurimonas, sulfitobacter, Desulfuromonas, Desulfobulbus and Desulfurococcales genera, suggests the presence of sulfur-oxidizers and sulfate-reducers in deep-sea hydrothermal vent sediments along the ELSC. Although the metabolic capabilities of phylotypes can not be directly determined from the phylogenetic relationship to cultured species, the 16S rRNA gene analysis supports the presence of putative sulfur-oxidizers and sulfate-reducers in our samples.

Sulfur is a key substrate at hydrothermal vents, particularly at higher temperatures, as a number of thermophilic and hyperthermophilic bacteria and archaea can use sulfur as an electron donor in either autotrophic or heterotrophic metabolis$\mathrm{m}$. In the present study, numerous sequences show high similarities with those related to sulfur metabolism. EpsilonProteobacteria belonging to Sulfuricurvum and Sulfurimonas genera identified in this study are typically sulfur oxidizers, which obtain energy through oxidation of some sulfur types, such as sulfide, thiosulfate and elemental sulfur (Takai et al., 2003; Inagaki et al., 2003b; López-Garcia et al., 2003). Some sequences which are similar to gammaproteobacterial endosymbionts, are also putative sulfur-oxidizers (Goffredi et al., 2004). Phylotypes related to Marinobacter and Natronocella sp. were also detected in the two hydrothermal samples, and representatives from both genera are capable of heterotrophic sulfur oxidation (Sorokin, 2003; Podgorsek et al., 2004). Reduction of oxidized sulfur compounds, as a part of deep-sea hydrothermal vent microbial metabolism, is mainly performed by DeltaProteobacteria that are comprised of phylotypes closely related to diverse genera (Desulfuromonas and Desulfobulbus) of sulfur- and sulfate-reducing bacteria. Additionally, the phylotype TVG11BA10 belonging to Alpha-Proteobacteria shared 99\% similarity with sequences of the sulfitobacter genera, which is involved in the oxidation of sulfite and would be important in 
the active sulfuretum. It is presumed that archaea belonging to the orders of Desulfurococcales, Thermoproteales, Archaeoglobales, and Thermococcales, are the important participaters in the sulfur metabolism, which were found to utilize $\mathrm{SO}_{4}^{2-}, \mathrm{S}_{2} \mathrm{O}_{3}^{2-}$, or $\mathrm{S}^{0}$ with $\mathrm{H}_{2} \mathrm{~S}$ as their ultimate metabolite (Sievert et al., 2007). Sulfur oxidation had been expected to be the primary energy metabolism driving deep-sea vent ecosystems (Nakagawa et al., 2005). It is generally thought that the mechanisms of sulfur oxidation in deep-sea vent ecosystems is different form shallow water environments, with the more various sulfur-metabolizing prokaryotes and more important ecological significance. Usually, sulfate is depleted in surface water environments but becomes available in deep-sea vent ecosystems, which may be used as an electron acceptor by a microbial consortium oxidizing methane.

In conclusion, this work demonstrates a diversity of bacteria and archaea, and also provided insights into microbial diversity in deep-sea hydrothermal fields along the ESLC in the Lau Back Arc Basin. Some sequences especially archaeal sequences were distantly related to these known so far and therefore we expanded the known diversity of microbes in deep-sea hydrothermal environments. Moreover, we provided a basis for further analysis of microbial sulfur metabolism mechanisms and ecological significance in deep-sea hydrothermal systems. In addition, we provided a guide to develop appropriate culturing methods for isolating novel indigenous bacteria and archaea.

\section{References}

Abildgaard L, Nielsen M B, Kjeldsen K U, et al. 2006. Desulfovibrio alkalitolerans sp. nov., a novel alkalitolerant, sulphate-reducing bacterium isolated from district heating water. Int J Syst Evo Microbiol, 56: 1019-1024

Brazelton W J, Schrenk M O, Kelley D S, et al. 2006. Methane- and Sulfur-Metabolizing Microbial Communities Dominate the Lost City Hydrothermal Field Ecosystem. Appl Environ Microbiol 72: 6257-6270

Campbell B J, Engel A S, Porter M L, et al. 2006. The versatile $\varepsilon$ proteobacteria: key players in sulphidic habitats. Nat Rev Microbiol, 4: 458-468

Ehrich S, Behrens D, Lebedeva E, et al. 1995. A new obligately chemolithoautotrophic, nitrite-oxidizing bacterium, Nitrospira moscoviensis sp.nov. and its phylogenetic relationship. Arch Microbiol, 164: 16-23

Fouquet Y, Vonstackelberg U, Charlou J L, et al. 1991. Hydrothermal activity and metallogenesis in the Lau back-arc basin. Nature, 349: 778-781

Fuhrman J A, Davis A A. 1997. Widespread archaea and novel bacteria from the deep-sea as shown by 16 s rRNA gene sequences. Mar Ecol Prog Ser, 150: 275-285

Fuhrman M, Davis J A, Kirkalison A. 1992. Novel major archaebacterial group from marine plankton. Nature, 356: 148-149

Goffredi S K, Waren A, Orphan V J, et al. 2004. Novel forms of structural integration between microbes and a hydrothermal vent gastropod from the Indian Ocean. Appl Environ Microbiol, 70: 3082-3090

Good I. 1953. The population frequencies of species and the estimation of population of parameters. Biometrika, 40: 237-264

Heijs S K, Laverman A M, Forney L J, et al. 2008. Comparison of deepsea sediment microbial communities in the eastern Mediterranean. FEMS Microbiol Ecol, 64: 362-377

Herzig P M, Hannington M D. 1995. Polymetallic massive sulfides at modern seafloor-A review. Ore Geol Rev, 10: 95-115

Hoek J, Banta A, Hubler F, et al. 2003. Microbial diversity of a sulphide spire located in the Edmond deep-sea hydrothermal vent filed on the Central Indian Ridge. Geobiology, 1: 119-127

Huber J A, Johnson H P, Butterfield D A, et al. 2005. Microbial life in ridge flank crustal fluids. Environ Microbiol, 8: 88-99
Inagaki F, Suzuki M, Takai K, et al. 2003a. Microbial communities associated with geological horizons in coastal subseafloor sediments from the sea of Okhotsk. Appl Environ Microbiol, 69: 7224-7235

Inagaki F, Takai K, Kobayashi H, et al. 2003b. Sulfurimonas autotrophica gen. nov., sp. nov., a novel sulfur-oxidizing epsilonproteobacterium isolated from hydrothermal sediments in the mid-Okinawa Trough. Int J Syst Evol Microbiol, 53: 1801-1805

Jeanthon C. 2000. Molecular ecology of hydrothermal vent microbial communities. Antonie van Leeuwenhoek, 77: 117-133

Kormas K A, Tivey M K, Damm K V, et al. 2006. Bacterial and archaeal phylotypes associated with distinct mineralogical layers of a white smoker spire from a deep-sea hydrothermal vent site $\left(9^{\circ} \mathrm{N}\right.$, East Pacific Rise). Environ Microbiol, 8: 909-920

Lauritzen S, Bottrell S. 1994. Microbial activity in thermoglacial karst springs, south Spitsbergen. Geomicrobiol J, 12: 161-173

López-García P, Duperron S, Philippot P, et al. 2003. Bacterial diversity in hydrothermal sediment and epsilonproteobacterial dominance in experimental microcolonizers at the Mid-Atlantic Ridge. Environ Microbiol, 5: 961-976

López-García P, López-López A, Moreira D, et al. 2001. Diversity of free-living prokaryotes from a deep-sea site at the Antarctic Polar Front. FEMS Microbiol Ecol, 36: 193-202

Magurran A. 1988. Ecological Diversity and Its Measurement. Princeton: Princeton University Press

Massana R, DeLong E F, Pedros-Alio C. 2000. A few cosmopolitan phylotypes dominate planktonic archaeal assemblages in widely different oceanic provinces. Appl Environ Microbiol, 66: 17771787

McCollom T M, Shock E L. 1997. Geochemical constraints on chemolithoautotrophic metabolism by microorganisms in seafloor hydrothermal systems. Geochim Cosmochim Acta, 61: 4375-4391

Michael P, Seewald J. 2007. Focus on: studies at the Lau Basin. Ridge 2000 Events, 2: 11-21

Miroshnichenko M L, Bonch-Osmolovskaya E A. 2006. Recent developments in the thermophilic microbiology of deep-sea hydrothermal vents. Extremophiles, 10: 85-96

Moussard H, Corre E, Cambon-Bonavita M A, et al. 2006. Novel uncultured Epsilonproteobacteria dominate a filamentous sulphur mat from the $13^{\circ} \mathrm{N}$ hydrothermal vent field, East Pacific Rise. FEMS Microbiol Lett, 58: 449-463

Muyzer G, Hottentrager S, Teske A, et al. 1996. Denaturing gradient gel electrophoresis of PCR-amplified 16S rDNA a new molecular approach to analyze the genetic diversity of mixed microbial communities. In: Akkermans A D L, Elsas J D, Bruijn F J, eds. Molecular Microbial Ecology Manual. Dordrecht, The Netherlands: Kluwer, 1-23

Nakagawa S, Takai K, Inagaki F, et al. 2005. Distribution, phylogenetic diversity and physiological characteristics of epsilonProteobacteria in a deep-sea hydrothermal field. Environ Microbiol, 7: 1619-1632

Nercessian O, Fouquet Y, Pierre C, et al. 2005. Diversity of Bacteria and Archaea associated with a carbonate-rich metalliferous sediment sample from the Rainbow vent field on the Mid-Atlantic Ridge. Environ Microbiol, 7: 698-714

Ovreas L, Forney L, Daae F L, et al. 1997. Distribution of bacterioplankton in meromictic Lake Saelenvannet, as determined by denaturing gradient gel electrophoresis of PCR-amplified gene fragments coding for 16S rRNA. Appl Environ Microbiol, 63: 3367-3373

Page A, Tivey M K, Stakes D S, et al. 2008. Temporal and spatial archaeal colonization of hydrothermal vent deposits. Environ Microbiol, 10: 874-884

Parkes R J, Webster G, Cragg B A, et al. 2005. Deep sub-seafloor prokaryotes stimulated at interfaces over geological time. Nature, 436: 390-394

Pernthaler A, Preston C M, Pernthaler J, et al. 2002. Comparison of fluorescently labeled oligonucleotide and polynucleotide probes for the detection of pelagic marine bacteria and archaea. Appl Environ Microbiol, 68: 661-667 
Podgorsek L, Petri R, Imhoff J. 2004. Cultured and genetic diversity, and activities of sulfur-oxidizing bacteria in low-temperature hydrothermal fluids of the North Fiji Basin. Mar Ecol Prog Ser, 266: $65-76$

Ravenschlag K, Sahm K, Amann R. 2001. Quantitative molecular analysis of the microbial community in marine Arctic sediments (Svalbard). Appl Environ Microbiol, 67: 387-395

Reysenbach A-L, Liu Y, Banta A B, et al. 2006. A ubiquitous thermoacidophilic archaeon from deep-sea hydrothermal vents. Nature, 442: 444-447

Rogers K L, Amend J P. 2005. Archaeal diversity and geochemical energy yields in a geothermal well on vulcano island, Italy. Geobiology, 3: 319-332

Rohlf F J. 2002. NTSYS-pc: Numerical Taxonomy System Ver. 2.1. Setauket, New York: Exeter Publishing Ltd.

Schrenk M O, Kelley D S, Delaney J R, et al. 2003. Incidence and diversity of microorganisms within the walls of an active deep-sea sulfide chimney. Appl Environ Microbiol, 69: 3580-3592

Sievert S, Kiene R P, Schultz-Vogt H N. 2007. The Sulfur Cycle. Oceanography, 20: 117-123

Sorokin D. 2003. Oxidation of inorganic sulfur compounds by obligately organotrophic bacteria. Microbiology, 72: 641-653

Takai K, Horikoshi K. 1999. Genetic diversity of archaea in deep-sea hydrothermal vent environments. Genet Soc Am, 152: 1285 1297

Takai K, Inagaki F, Nakagawa S, et al. 2003. Isolation and phylogenetic diversity of members of previously uncultivated Proteobacteria in deep-sea hydrothermal fields. FEMS Microbiol Lett, 218:
$6167-6174$

Takai K, Nunoura T, Ishibashi J I, et al. 2008. Variability in the microbial communities and hydrothermal fluid chemistry at the newly discovered mariner hydrothermal field, southern Lau Basin. J Geophys Res, 113: G02031

Teske A. 2006. Microbial communities of deep marine subsurface sediments: Molecular and cultivation surveys. Geomicrobiol, 23: 357-368

Van Dover C L. 2000. The Ecology of Deep-Sea Hydrothermal Vents. Princeton: Princeton University Press

Vandieken V, Mussmann M, Niemann H, et al. 2006. Desulfuromonas svalbardensis sp. nov. and Desulfuromusa ferrireducens $\mathrm{sp}$ nov., psychrophilic, Fe (III)-reducing bacteria isolated from Arctic sediments, Svalbard. Int J Syst Evol Microbiol, 56: 1133-1139

Vetriani C, Jannasch H W, Macgregor B J, et al. 1999. Population structure and phylogenetic characterization of marine benthic archaea in deep-sea sediments. Appl Environ Microbiol, 65: $4375-4384$

Wang Fengping, Zhou Huaiyang, Meng Jun, et al. 2009. Geochipbased analysis of metabolic diversity of microbial communities at the Juan de Fuca Ridge hydrothermal vent. Proc Natl Acad Sci USA, 106: 4840-4845

Zhou Jizhong, Bruns M A, Tiedje J M. 1996. DNA recovery from soils of diverse composition. Appl Environ Microbiol, 62: 316-322 